\title{
The combined effects of the microcirculatory status and cardiopulmonary bypass on platelet count and function during cardiac surgery
}

\author{
Umberto Di Dedda $^{\mathrm{a}}$, Marco Ranucci ${ }^{\mathrm{a}, *}$, Alberto Porta $^{\mathrm{a}, \mathrm{b}}$, Vlasta Bari ${ }^{\mathrm{a}}$, Alice Ascari ${ }^{\mathrm{a}}$, \\ Angela Fantinato ${ }^{a}$, Ekaterina Baryshnikova ${ }^{a}$ and Mauro Cotza ${ }^{a}$ \\ ${ }^{a}$ Department of Cardiothoracic, Vascular Anesthesia and Intensive Care, IRCCS Policlinico \\ San Donato, San Donato Milanese, Milan, Italy \\ ${ }^{\mathrm{b}}$ Department of Biomedical Sciences for Health, University of Milan, Milan, Italy
}

\begin{abstract}
.
BACKGROUND: Cardiac surgery with cardiopulmonary bypass is associated with important changes in the microcirculation, usually attributed to endothelial dysfunction. Another common finding of cardiac surgery is postoperative thrombocytopenia and platelet loss of function.

OBJECTIVE: To investigate the association between microvascular flow pattern and postoperative changes in platelet count and function in cardiac surgery patients.

METHODS: Twelve adult cardiac surgery patients received microvascular circulation (sidestream darkfield sublingual mucosa analysis) and platelet count and function (multiple electrode aggregometry ADPtest and TRAPtest) assessment before and after cardiopulmonary bypass.

RESULTS: After cardiopulmonary bypass, sublingual microcirculation showed a significantly $(P=0.001)$ decreased microvascular flow index and increased heterogeneity index $(P=0.006)$. Platelet function significantly decrease after cardiopulmonary bypass both at ADPtest $(P=0.011)$ and TRAPtest $(P=0.002)$. Preoperative patterns of poor microvascular perfusion (low perfused vessels density and total vessels density) were significantly associated with lower values of postcardiopulmonary bypass platelet function (ADPtest, $P=0.009$, TRAPtest, $P=0.031$ ) and count $(P=0.048)$.

CONCLUSIONS: A preoperative disturbance of the microcirculation is associated with a greater postoperative platelet dysfunction. Endothelial damage, chemical and mechanical stimuli are the possible link between the two patterns.
\end{abstract}

Keywords: Cardiac surgery, sublingual microcirculation, platelet function, multiple electrode aggegometry

\section{Introduction}

Patients at increased cardiovascular risk show endothelial glycocalyx and microvascular perturbations [1-3]. This condition has been advocated as a determinant of microvascular angina [4]. Patients with coronary disease have activated circulating platelets, a decreased platelet reactivity and an elevated platelet adhesion $[5,6]$. When myocardial ischemia is determined by multiple coronary lesions, coronary artery bypass graft $(\mathrm{CABG})$ surgery is still the gold standard. Coronary surgery, with or without cardiopulmonary bypass (CPB) is accompanied by well-known microcirculatory alterations

\footnotetext{
*Corresponding author: Marco Ranucci, M.D., Director of Clinical Research of the IRCCS Policlinico San Donato, Via Morandi 30, 20097 San Donato Milanese, Milan, Italy. Tel.: +39 02 5277754; Fax: +39 02 55602262; E-mail: cardioanestesia@virgilio.it.
} 
due to a number of mechanisms, including hemodilution, non-pulsatile flow, release of inflammatory cytokines, platelet activation, and others [7-9].

Coronary surgery with $\mathrm{CPB}$ has an important impact on platelet count and function: due to the extensive release of tissue factor, platelets are activated and post-CPB platelet dysfunction is a common pattern $[10,11]$. Additionally, platelet adhesion to the foreign surfaces of CPB circuit and oxygenator, as well as to the activated endothelial surface, together with blood loss concur in the determination of variable patterns of thrombocytopenia. Platelet adhesion is accompanied by activation, release reaction and spreading [12]. This also leads to an activation of the circulating platelets.

Platelet activation is a complex phenomenon involving chemical and mechanical factors. Among the latter, shear-stress plays an important role as a platelet activator, and impaired microcirculatory conditions may create the substrate for platelet adhesion, activation, and loss of count and function. Therefore, coronary surgery with CPB represents an interesting setting where pre-operative endothelial dysfunction, intraoperative microvascular impairment, and platelet activation are simultaneously present and may concur in determining post-operative organ dysfunction [13-16].

The present study investigates the changes in platelet count and function in the setting of coronary surgery with $\mathrm{CPB}$, and in relation to the pre and post-CPB conditions of the microcirculation.

\section{Material and methods}

Prospective cohort study conducted at the cardiac anesthesia and intensive care department of the IRCCS Policlinico San Donato between October 2017 and January 2018. Data from this study were obtained by two ongoing prospective cohort studies registered at clinicaltrials.gov with identifier codes NCT03169608 (microcirculation) and NCT03121898 (platelet function). The studies were approved by the local Ethics Committee of the IRCCS San Raffaele Hospital, and all the patients provided a written informed consent.

\subsection{Patients}

The study included twelve adult patients receiving CABG surgery (with or without additional procedures) at our institution. All the patients were operated under elective conditions and were free from the effects of anti-platelet agents acting on the $\mathrm{P}_{2} \mathrm{Y}_{12}$ receptor. Aspirin treatment was not discontinued.

\subsection{Surgery, anesthesia, and $C P B$}

According to our standard practice, the patients received a premedication with intramuscular atropine $(0.5 \mathrm{mg})$ and fentanyl $(100 \mu \mathrm{g})$ about 1 hour before reaching the operating theater. Anesthesia was induced with an intravenous bolus injection of propofol at $1.5 \mathrm{mg} \cdot \mathrm{kg}^{-1}$ and infusion of remifentanil $0.2 \mu \mathrm{g} \cdot \mathrm{kg}^{-1} \cdot \mathrm{min}^{-} 1 \cdot$ Maintenance of anesthesia was achieved with a continuous infusion of propofol at $3 \mathrm{mg} \cdot \mathrm{kg}^{-1} \cdot \mathrm{h}^{-1}$ and a remifentanil infusion range from 0.05 to $0.5 \mu \mathrm{g} \cdot \mathrm{kg}^{-1} \cdot \mathrm{min}^{-1} \cdot$ Additional inhalatory agents (sevorane) could be used as requested.

CPB was conducted using open circuits, phosphorylcholine coated hollow-fiber oxygenators, and centrifugal pumps. Regardless of the circuit used, the priming volume was always minimized to 600-800 mL. The lowest temperature on CPB was decided by the surgeon, but was kept within a range of $32{ }^{\circ} \mathrm{C}-34{ }^{\circ} \mathrm{C}$. The $\mathrm{CPB}$ flow was adjusted in order to maintain a mean perfusion pressure in the range of $60-80 \mathrm{mmHg}$ and adequate oxygen delivery. If needed, systemic vasoconstrictor (norepinephrine) or vasodilator (sodium nitroprusside) infusions were used in order to keep the perfusion pressure within the range. Cold crystalloid or blood cardioplegia were used according to the surgeon's preference. 


\subsection{Data collection and definitions}

The following perioperative data were collected: demographics; family history of coronary disease; dyslipidemia; hypertension; serum creatinine levels ( $\mathrm{mg} / \mathrm{dL})$; hematocrit $(\%)$ before $\mathrm{CPB}$, nadir value on $\mathrm{CPB}$, and after weaning from $\mathrm{CPB}$; platelet count $(\mathrm{x} 1,000$ cells $/ \mu \mathrm{L})$ before $\mathrm{CPB}$ and at the end of the procedure; diabetes (on medication); ongoing use of beta-blockers, angiotensin converting enzyme inhibitors, diuretics, calcium antagonists, aspirin; CPB duration (minutes); fluid administration before $\mathrm{CPB}$; priming volume $(\mathrm{mL})$; type of surgery; transfusions of red blood cells; use of inotropic/vasoactive drugs (dopamine, epinephrine, nor-epinephrine) for CPB weaning.

At two points in time (after induction of anesthesia before surgical incision, and after weaning from $\mathrm{CPB}$ ) platelet function and microcirculation status were assessed as subsequently explained.

\subsection{Platelet function assessment}

ADP-dependent and thrombin-dependent platelet aggregability were assessed using a multipleelectrode aggregometry (MEA, Multiplate, Roche Diagnostics, Indianapolis, IN).

An amount of $3 \mathrm{~mL}$ of blood was drawn from a venous line and collected in hirudin-coated tubes provided by the manufacturer. Platelet function tests were performed within 30 minutes from the arrival in our point-of-care coagulation laboratory, that is situated in the operating room, and after 30 minutes from blood collection.

Platelet aggregation testing on the MEA analyzer was performed as follows. Briefly, $300 \mu \mathrm{L}$ of whole blood were added to an equal amount of preheated saline solution and platelet aggregation was tested after specific activation with adenosine diphosphate (ADP, ADPtest, $6.5 \mu \mathrm{M}$ final concentration) and thrombin-activating peptide (TRAP-6, TRAPtest, $32 \mu \mathrm{M}$ final concentration). $\mathrm{P}_{2} \mathrm{Y}_{12}$ receptors are inhibited by direct ADP receptor inhibitors (clopidogrel, ticlopidine, prasugrel and ticagrelor), whereas TRAP test is sensitive to GPIIbIIIa inhibitors and, being a potent platelet activator via thrombin receptors, in the absence of specific inhibiting drugs, represents the "natural" maximum aggregation potential of the platelets. Platelet aggregation was electronically measured for 6 minutes and expressed as units of area under the curve plotted over time (AUC, [U]).

Normal reference range for ADPtest is 57-113 (U) and for TRAPtest is 84-128 (U).

Platelet reactivity at MEA is routinely performed in two parallel channels, to check for intra-test variability. The test was planned to be repeated if the results differed more than the reference range provided by the manufacturer.

\subsection{Microcirculation assessment}

A proper evaluation of microcirculatory status should include an assessment of vascular density, capillary perfusion and the heterogeneity of perfusion.

For such purpose a number of microcirculatory parameters have been employed in clinical practice. Briefly, the De Backer score approximates vessel density using a line-crossing method. Total vessel density (TVD, $\mathrm{mm} / \mathrm{mm}^{2}$ ) is another measure of vessel density, while perfused vessel density (PVD $\mathrm{mm} / \mathrm{mm}^{2}$ ) and proportion of perfused vessels (PPV,\%) correspond to the density of functionally flowing capillaries. PPV refers to the percentage of perfused vessels with respect to the total vessels in each sequence.

The microvascular flow index (MFI) is a semi-quantitative measure of capillary perfusion quality. Perfused vessels are those with a constant or sluggish flow, and non-perfused vessels are those with intermittent or absent flow. 
Finally, the Heterogeneity Index (HI) evaluates the heterogeneity or variability of predominant blood flow between sequences at a single time point at different sites of detection.

The sublingual microcirculation was evaluated at four different sites using sidestream dark field (SDF) videomicroscopy (Microscan, Microvision Medical, Amsterdam, NL). Four images per timepoint were analyzed using the Automated Vascular Analysis (AVA) software version 4.1 (Microvision Medical BV). TVD, PVD, De Backer score [17], PPV,MFI, and HI were calculated. The SDF was extensively described elsewhere [18, 19]. Briefly, in SDF imaging, illumination is provided by surrounding a central light guide by concentrically placed light emitting diodes (LEDs). The lens system in the core of the light guide is optically isolated from the illuminating outer ring. Light from the SDF probe penetrates the tissue and illuminates the tissue-embedded microcirculation by scattering. The LEDs emit at a central green wavelength to ensure optimal optical absorption by the hemoglobin in the RBCs, independent of its oxygenation state. In the final image, RBCs are imaged as dark moving globules against a white/grayish background. To improve the imaging of flowing RBCs, the LEDs provide pulsed illumination [18, 19].

The saliva was gently removed with gauzes and the SDF probe was then positioned under the tongue. Thereafter, four consecutive videos were recorded at different areas of the sublingual mucosa.

The SDF images were recorded at two points in time: after the induction of anesthesia and before $\mathrm{CPB}$; and after weaning from $\mathrm{CPB}$.

The values of PPV, TVD, PVD, and De Backer score were automatically produced by the AVA 4.1 software. Conversely, MFI and HI were calculated off-line by visual analysis. Perfusion was categorized by eye as absent (0), intermittent (1), sluggish (2), or normal (3) and then we calculated the average values of the four quadrants. Finally, the heterogeneity index (HI) was calculated taking into account the highest site flow velocity minus the lowest site flow velocity, divided by the mean flow velocity of all sublingual sites [20].

\subsection{Statistics}

Continuous variables are presented as median with interquartile range in text, and tables and as median, interquartile range, and $95 \%$ confidence interval in figures. Binary variables are presented as number and percentage.

Differences between the continuous variables measured before and after CPB were tested with non-parametric tests for related samples (Wilcoxon test).

Associations between continuous variables were tested using Pearson's correlation matrixes producing correlation coefficients (R) and $P$ values. All tests were two-sided; a $P$ value $<0.05$ was considered statistically significant.

The association between continuous variables being significant at the correlation matrix were subsequently explored using linear and non-linear regression analyses, producing the best-fit relationship with $95 \%$ confidence interval, squared correlation coefficient $\left(\mathrm{R}^{2}\right)$ and $P$ values for association.

All the analyses were performed using computerized statistical packages (SPPS 13.0, IBM, Chicago, IL, and GraphPad Prism 7.0, GraphPad Software, Inc., La Jolla, CA).

\section{Results}

Table 1 reports the general characteristics of the patient population. Microcirculation parameters before and after CPB are reported in Fig. 1. After CPB there was a significant $(P=0.001)$ decrease of the MFI and a significant $(P=0.006)$ increase of the HI. The De Backer score (not in Fig. 1) did not significantly change $(P=0.943)$ from before (median 11.8 , interquartile range $11.1-12.6)$ to after 
Table 1

General characteristics of the patient population $(\mathrm{N}=12)$

\begin{tabular}{|c|c|}
\hline Factor & Value \\
\hline Age (years) & $69.5(64.2-79.2)$ \\
\hline Weight (kgs) & $69(65-74.5)$ \\
\hline Height (cms) & $167(160-169.5)$ \\
\hline Gender male/female & $10(82.3) / 2(17.7)$ \\
\hline History of coronary disease & $1(8.3)$ \\
\hline Serum creatinine (mg/dL) & $0.87(0.80-1.08)$ \\
\hline Hypertension & $8(66)$ \\
\hline Diabetes on medication & $5(41.7)$ \\
\hline Dyslipidemia & $6(50)$ \\
\hline \multicolumn{2}{|l|}{ Ongoing drugs } \\
\hline Beta-blockers & $6(50)$ \\
\hline ACE-inhibitors & $5(41.7)$ \\
\hline Calcium antagonists & $1(8.3)$ \\
\hline Diuretics & $7(58.3)$ \\
\hline Aspirin & $4(33.3)$ \\
\hline \multicolumn{2}{|l|}{ Hematocrit (\%) } \\
\hline Baseline & $39(36.3-40.7)$ \\
\hline Nadir on CPB & $27(24.2-30)$ \\
\hline After weaning from $\mathrm{CPB}$ & $28.5(26.5-32)$ \\
\hline \multicolumn{2}{|l|}{ Platelet count $(\mathrm{x} 1,000$ cells $/ \mu \mathrm{L})$} \\
\hline Baseline & $224(182-246)$ \\
\hline End procedure & $147(111-178)$ \\
\hline \multicolumn{2}{|l|}{ Surgery } \\
\hline Isolated CABG & $6(50)$ \\
\hline $\mathrm{CABG}+$ valve procedure & $6(50)$ \\
\hline CPB duration (min) & $80(57-106)$ \\
\hline Nadir temperature on CPB $\left({ }^{\circ} \mathrm{C}\right)$ & $31.8(31.3-32.5)$ \\
\hline Fluids before CPB (mL) & $850(800-1125)$ \\
\hline Priming volume $(\mathrm{mL})$ & $700(700-800)$ \\
\hline Red blood cells transfusions & $2(16.7)$ \\
\hline Inotropic drugs at CPB weaning & $5(41.7)$ \\
\hline
\end{tabular}

ACE: angiotensin converting enzyme; $\mathrm{CABG}$ : coronary artery bypass graft; $\mathrm{CPB}$ : cardiopulmonary bypass. Data are number $(\%)$ or median (interquartile range).

CPB (median 11.3, interquartile range 11.2-11.8). Platelet count and function parameters are reported in Fig. 2. After CPB, platelet count significantly decreased, as well as platelet function at both the ADPtest and the TRAPtest.

The association between microcirculation parameters and platelet-related parameters were investigated with a correlation matrix, reported in Table 2.

No significant association was found between post-CPB microcirculation parameters and any parameter related to platelet count or function. Pre- CPB PPV, MFI and HI did not show any significant association with any parameter related to platelet count and function.

There were significant associations between pre-CPB PVD, TVD, De Backer score and parameters of platelet count/function. In details, higher values of pre-CPB PVD were associated with a greater postCPB platelet count $(P=0.048)$, a higher post-CPB ADPtest $(P=0.009)$ and TRAPtest $(P=0.031)$, and a lower decrease of platelet count from pre to post-CPB $(P=0.017)$. Similar results were mirrored by 


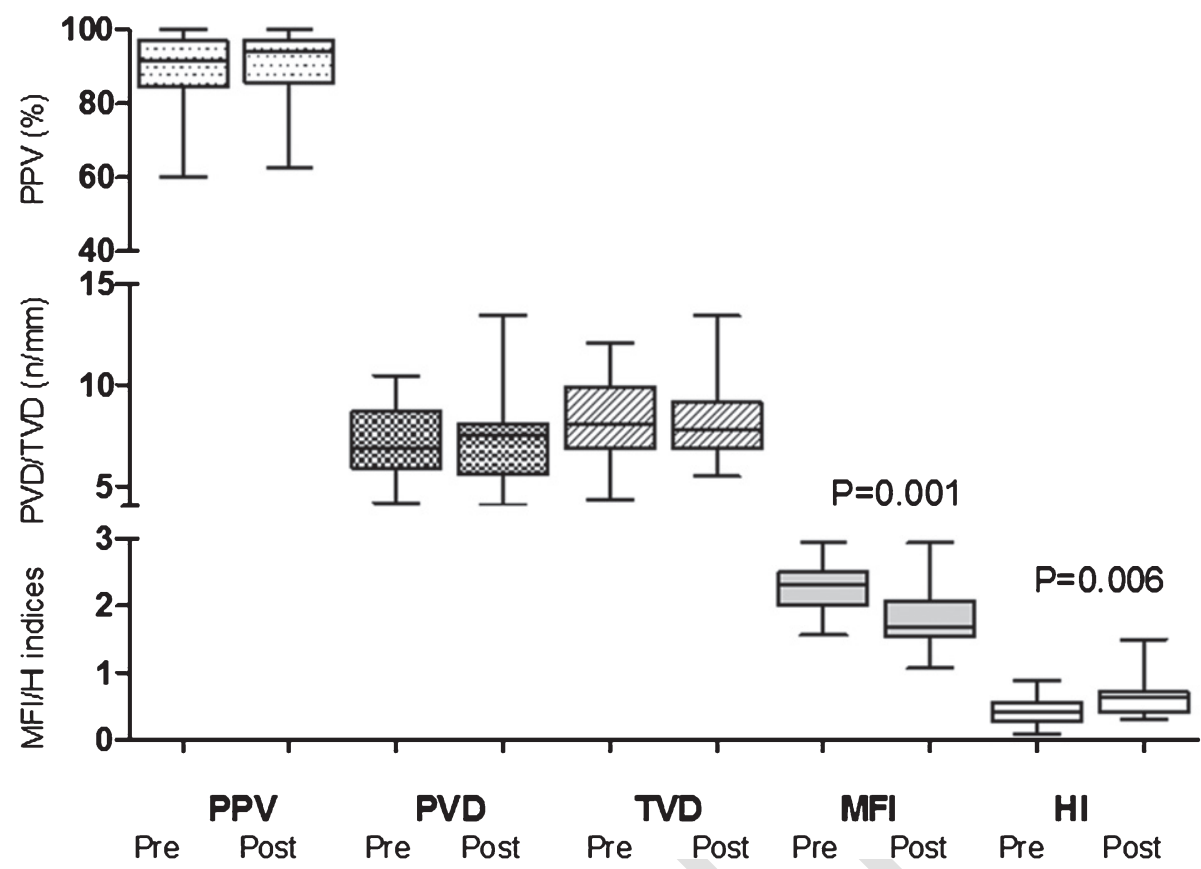

Fig. 1. Microcirculation parameters before (pre) and after (post) cardiopulmonary bypass. HI: heterogeneity index; MFI: microvascular flow index; PPV: proportion of perfused vessels; PVD: perfused vessels density; TVD: total vessels density. Boxes are interquartile range, lines in the box are median, whiskers are $95 \%$ confidence interval.

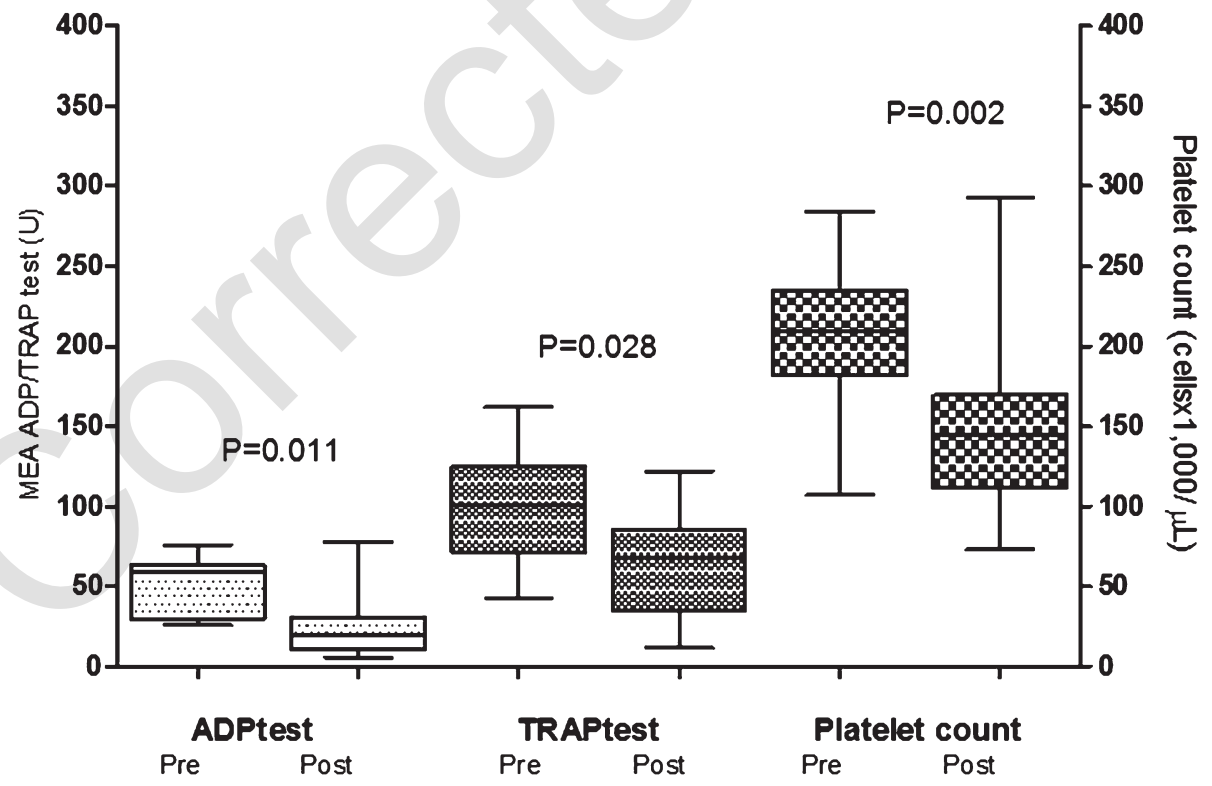

Fig. 2. Platelet count and function before (pre) and after (post) cardiopulmonary bypass. MEA: multiple electrode aggregometry. Boxes are interquartile range, lines in the box are median, whiskers are $95 \%$ confidence interval.

the pre-CPB TVD, with a higher post-CPB ADPtest $(P=0.021)$ and lower decreases (from pre to post$\mathrm{CPB})$ of platelet count $(P=0.043)$ and function at the ADPtest $(P=0.006)$ and TRAPtest $(P=0.039)$. Finally, a higher De Backer score was associated with a higher post-CPB ADPtest $(P=0.014)$. 
Table 2

Association between microcirculation parameters and platelet function tests $(\mathrm{N}=12)$

\begin{tabular}{|c|c|c|c|c|c|c|c|c|c|c|c|c|}
\hline $\operatorname{ara}$ & $\begin{array}{c}\text { PPVpre } \\
(\%)\end{array}$ & $\begin{array}{l}\text { PVDpre } \\
\left(\mathrm{n} / \mathrm{mm}^{2}\right)\end{array}$ & $\begin{array}{l}\text { TVDpre } \\
\left(\mathrm{n} / \mathrm{mm}^{2}\right)\end{array}$ & $\begin{array}{l}\text { Backer } \\
\text { pre }\end{array}$ & MFIpre & $\begin{array}{l}\text { Hipre } \\
(\%)\end{array}$ & $\begin{array}{c}\text { PPVpost } \\
(\%)\end{array}$ & $\begin{array}{l}\text { PVDpost } \\
\left(\mathrm{n} / \mathrm{mm}^{2}\right)\end{array}$ & $\begin{array}{l}\text { post } \\
\left.n^{2}\right)\end{array}$ & $\begin{array}{c}\text { De Backer } \\
\text { post }\end{array}$ & MFIpost & $\begin{array}{c}\text { Hipost } \\
(\%)\end{array}$ \\
\hline $\begin{array}{l}\text { PLTcount preCPB } \\
\text { (cells/ } \mu \mathrm{L})\end{array}$ & $P=0.601$ & $\begin{array}{l}\mathrm{R}=0.006 \\
P=0.981\end{array}$ & $\begin{array}{c}\mathrm{R}=-0.075 \\
P=0.776\end{array}$ & $\begin{array}{c}\mathrm{R}=-0.056 \\
P=0.832\end{array}$ & $\begin{array}{c}\mathrm{R}=-0.355 \\
P=0.161\end{array}$ & $\begin{array}{l}\mathrm{R}=-0 \\
P=0 .\end{array}$ & $P=0.769$ & 561 & $\begin{array}{l}\mathrm{R}= \\
P=\end{array}$ & $\begin{array}{l}77 \\
81\end{array}$ & $\begin{array}{c}\mathrm{R}=-0.177 \\
P=0.497\end{array}$ & $\begin{array}{c}\mathrm{R}=-0.094 \\
P=0.721\end{array}$ \\
\hline $\begin{array}{l}\text { ADPtest } \\
\text { preCPB (U) }\end{array}$ & $\begin{array}{l}\mathrm{R}=0 \\
P=0\end{array}$ & $\begin{array}{l}\mathrm{R}= \\
P=\end{array}$ & $\begin{array}{c}\mathrm{R}=-0.2 \\
P=0.4\end{array}$ & $\begin{array}{l}\mathrm{R}=0.320 \\
P=0.310\end{array}$ & $\begin{array}{l}=-0.253 \\
=0.408\end{array}$ & $\begin{array}{l}\mathrm{R}= \\
P=\end{array}$ & $\begin{array}{l}\mathrm{R}=0 \\
P=0\end{array}$ & 12 & $\begin{array}{l}\mathrm{R}= \\
P=\end{array}$ & $\begin{array}{l}0.130 \\
0.688\end{array}$ & 40 & $\begin{array}{l}\mathrm{R}=0.225 \\
P=0.482\end{array}$ \\
\hline preCPB & $\begin{array}{l}\mathrm{R}=0.508 \\
P=0.092\end{array}$ & $\begin{array}{l}\mathrm{R}=0.037 \\
P=0.908\end{array}$ & $\begin{array}{c}\mathrm{R}=-0.239 \\
P=0.404\end{array}$ & $\begin{array}{l}\mathrm{R}=0.276 \\
P=0.385\end{array}$ & $\begin{array}{c}\mathrm{R}=-0.034 \\
P=0.916\end{array}$ & $\begin{array}{l}\mathrm{R}=0.149 \\
P=0.644\end{array}$ & $\begin{array}{l}\mathrm{R}=0 \\
P=0\end{array}$ & $\begin{array}{l}\mathrm{R}=0.230 \\
P=0.473\end{array}$ & $\begin{array}{l}87 \\
61\end{array}$ & $\begin{array}{l}13 \\
32\end{array}$ & $\begin{array}{l}114 \\
724\end{array}$ & $\begin{array}{l}\mathrm{R}=0.126 \\
P=0.695\end{array}$ \\
\hline stCPB & $\begin{array}{l}\mathrm{R}=0 \\
P=0\end{array}$ & $\begin{array}{l}\mathrm{R}=0 \\
P=0\end{array}$ & $\begin{array}{l}\mathrm{R}=\mathrm{c} \\
P=\mathrm{C}\end{array}$ & $\begin{array}{l}\mathrm{R}=0 . \\
P=0 .\end{array}$ & $\begin{array}{l}\mathrm{R}=0.128 \\
P=0.625\end{array}$ & $\begin{array}{c}\mathrm{R}=-0.169 \\
P=0.518\end{array}$ & $\begin{array}{l}\mathrm{R}=-( \\
P=0\end{array}$ & 293 & $\begin{array}{l}244 \\
44\end{array}$ & $\begin{array}{l}34 \\
09\end{array}$ & $\begin{array}{l}18 \\
51\end{array}$ & $\begin{array}{l}210 \\
409\end{array}$ \\
\hline $\begin{array}{l}\text { ADPtest } \\
\text { postCPB (U) }\end{array}$ & $\begin{array}{l}\mathrm{R}=0.123 \\
P=0.702\end{array}$ & $\begin{array}{c}\mathrm{R}=0.707 \\
P=0.009 * *\end{array}$ & $\begin{array}{c}\mathrm{R}=0.653 \\
P=0.021 *\end{array}$ & $\begin{array}{c}\mathrm{R}=0.687 \\
P=0.014^{*}\end{array}$ & $\begin{array}{c}\mathrm{R}=-0.006 \\
P=0.985\end{array}$ & $\begin{array}{l}\mathrm{R}=0.138 \\
P=0.669\end{array}$ & $\begin{array}{c}\mathrm{R}=-0.375 \\
P=0.229\end{array}$ & $\begin{array}{c}\mathrm{R}=- \\
P=\end{array}$ & $\begin{array}{l}\mathrm{R}= \\
P=\end{array}$ & $\begin{array}{c}\mathrm{R}=- \\
P=\end{array}$ & $\begin{array}{l}346 \\
271\end{array}$ & $\begin{array}{r}\mathrm{R}=-0 \\
P=0\end{array}$ \\
\hline $\begin{array}{l}\text { TRAP } \\
\text { postCF }\end{array}$ & $\begin{array}{l}\mathrm{R}=0.211 \\
P=0.511\end{array}$ & $\begin{array}{c}\mathrm{R}=0.621 \\
P=0.031 *\end{array}$ & $\begin{array}{l}\mathrm{R}=0.510 \\
P=0.090\end{array}$ & $\begin{array}{l}\mathrm{R}=0.543 \\
P=0.068\end{array}$ & $\begin{array}{l}\mathrm{R}=0.308 \\
P=0.330\end{array}$ & $\begin{array}{c}\mathrm{R}=-0.088 \\
P=0.786\end{array}$ & $\begin{array}{c}\mathrm{R}=-0.442 \\
P=0.151\end{array}$ & $\begin{array}{c}\mathrm{R}=-0.174 \\
P=0.588\end{array}$ & $\begin{array}{l}\mathrm{R}= \\
P=\end{array}$ & $\begin{array}{c}\mathrm{R}=-0.122 \\
P=0.705\end{array}$ & $\begin{array}{l}\mathrm{R}=- \\
P=\end{array}$ & $\begin{array}{c}\mathrm{R}=-0.417 \\
P=0.177\end{array}$ \\
\hline $\begin{array}{l}\text { DeltaPLTcount } \\
(\text { cells } / \mu \mathrm{L})\end{array}$ & $\begin{array}{c}\mathrm{R}=-0.088 \\
P=0.738\end{array}$ & $\begin{array}{l}\mathrm{R}=-0.568 \\
P=0.017 *\end{array}$ & $\begin{array}{l}\mathrm{R}=-0.496 \\
P=0.043 *\end{array}$ & $\begin{array}{c}\mathrm{R}=-0.349 \\
P=0.170\end{array}$ & $\begin{array}{c}\mathrm{R}=-0.199 \\
P=0.443\end{array}$ & $\begin{array}{c}\mathrm{R}=-0.179 \\
P=0.491\end{array}$ & $\begin{array}{l}\mathrm{R}=0.378 \\
P=0.135\end{array}$ & $\begin{array}{l}\mathrm{R}=0.416 \\
P=0.090\end{array}$ & $\begin{array}{c}\mathrm{R}=-0.425 \\
P=0.089\end{array}$ & $\begin{array}{c}\mathrm{R}=-0.432 \\
P=0.084\end{array}$ & $\begin{array}{l}\mathrm{R}=0.035 \\
P=0.895\end{array}$ & $\begin{array}{l}\mathrm{R}=0.155 \\
P=0.552\end{array}$ \\
\hline Delta & $\begin{array}{l}\mathrm{R}=0.318 \\
P=0.314\end{array}$ & $\begin{array}{c}\mathrm{R}=-0.564 \\
P=0.056\end{array}$ & $\begin{array}{c}\mathrm{R}=-0.737 \\
P=0.006^{* *}\end{array}$ & $\begin{array}{c}\mathrm{R}=-0.335 \\
P=0.287\end{array}$ & $\begin{array}{c}\mathrm{R}=-0.183 \\
P=0.570\end{array}$ & $\begin{array}{l}\mathrm{R}=0.214 \\
P=0.503\end{array}$ & $\begin{array}{l}\mathrm{R}=0.458 \\
P=0.134\end{array}$ & $\begin{array}{l}\mathrm{R}=0.236 \\
P=0.460\end{array}$ & $\begin{array}{c}\mathrm{R}=-0.050 \\
P=0.876\end{array}$ & $\begin{array}{l}\mathrm{R}=0.311 \\
P=0.324\end{array}$ & $\begin{array}{c}\mathrm{R}=-0.318 \\
P=0.314\end{array}$ & $\begin{array}{l}\mathrm{R}=0.497 \\
P=0.101\end{array}$ \\
\hline Delt & $\begin{array}{l}\mathrm{R}=0.266 \\
P=0.404\end{array}$ & $\begin{array}{c}\mathrm{R}=-0.453 \\
P=0.139\end{array}$ & $\begin{array}{l}\mathrm{R}=-0.600 \\
P=0.039 *\end{array}$ & $\begin{array}{c}\mathrm{R}=-0.190 \\
P=0.554\end{array}$ & $\begin{array}{c}\mathrm{R}=-0.269 \\
P=0.398\end{array}$ & $\begin{array}{l}\mathrm{R}=0.195 \\
P=0.544\end{array}$ & $\begin{array}{l}\mathrm{R}=0.425 \\
P=0.168\end{array}$ & $\begin{array}{l}\mathrm{R}=0.330 \\
P=0.294\end{array}$ & $\begin{array}{c}\mathrm{R}=-0.163 \\
P=0.862\end{array}$ & $\begin{array}{l}\mathrm{R}=0.445 \\
P=0.147\end{array}$ & $\begin{array}{c}\mathrm{R}=-0.278 \\
P=0.382\end{array}$ & $\begin{array}{l}\mathrm{R}=0.432 \\
P=0.160\end{array}$ \\
\hline
\end{tabular}

$*=P<0.05 ; * *=P<0.01$ 
The relationship between pre-CPB PVD and post-CPB ADPtest and TRAPtest are reported in Figs. 3 and 4 , respectively. The best fit for the ADPtest is defined by a cubic equation $\left(\mathrm{R}^{2}=0.600, P=0.015\right)$ and for the TRAPtest by a linear equation $\left(\mathrm{R}^{2}=0.386, P=0.031\right)$.

Figure 5 defines the relationship between pre-CPB TVD and the delta pre-post CPB ADPtest. The best association was found for a linear equation $\left(\mathrm{R}^{2}=0.544, P=0.006\right)$.

\section{Discussion}

The main finding of our study is that pre-CPB microcirculatory status determines significant changes in post-CPB platelet count and especially function. The most relevant associations are found for the

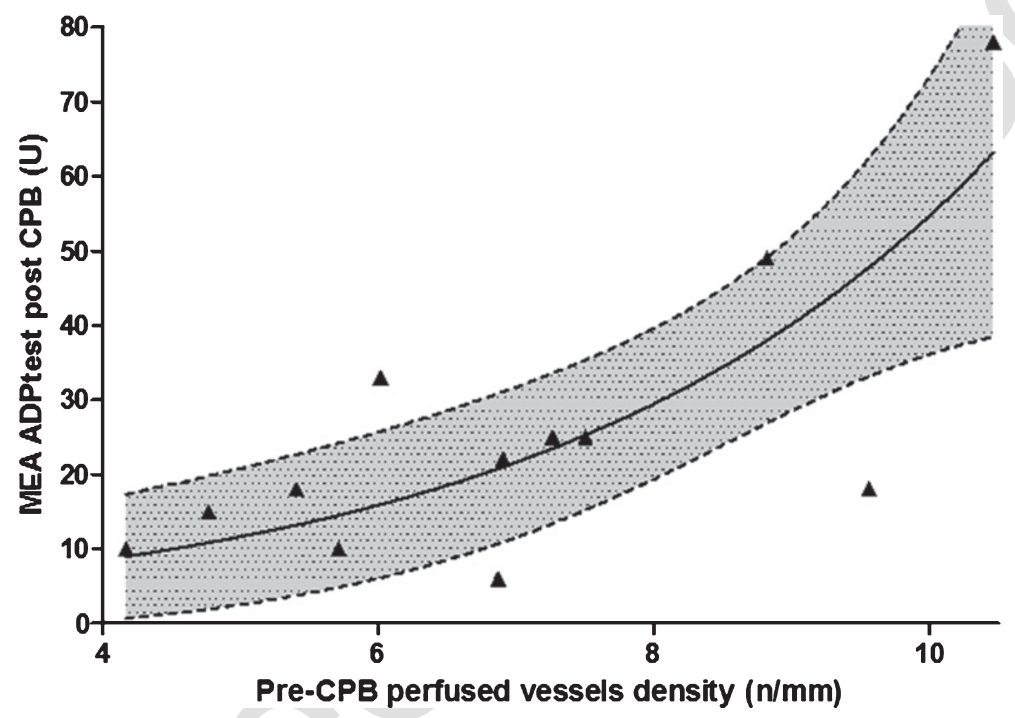

Fig. 3. Cubic regression analysis for association between pre-cardiopulmonary bypass (CPB) perfused vessels density and post-CPB multiple electrode aggregometry (MEA) ADPtest. Dashed lines delimit the 95\% confidence interval (gray zone).

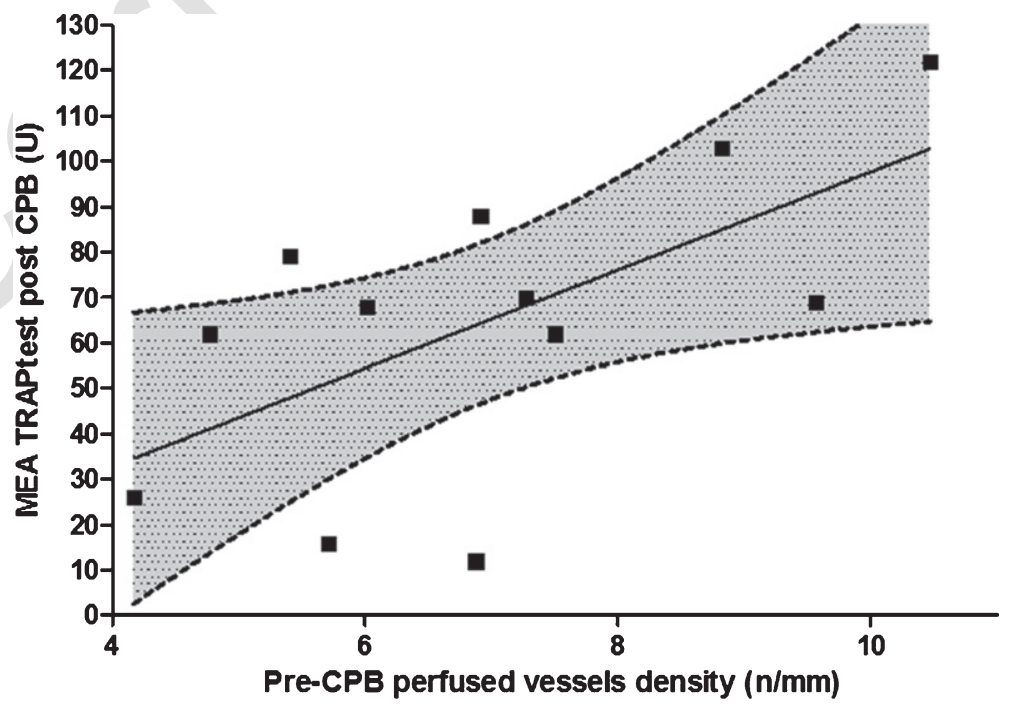

Fig. 4. Linear regression analysis for association between pre-cardiopulmonary bypass (CPB) perfused vessels density and post-CPB multiple electrode aggregometry (MEA) TRAPtest. Dashed lines delimit the $95 \%$ confidence interval (gray zone). 


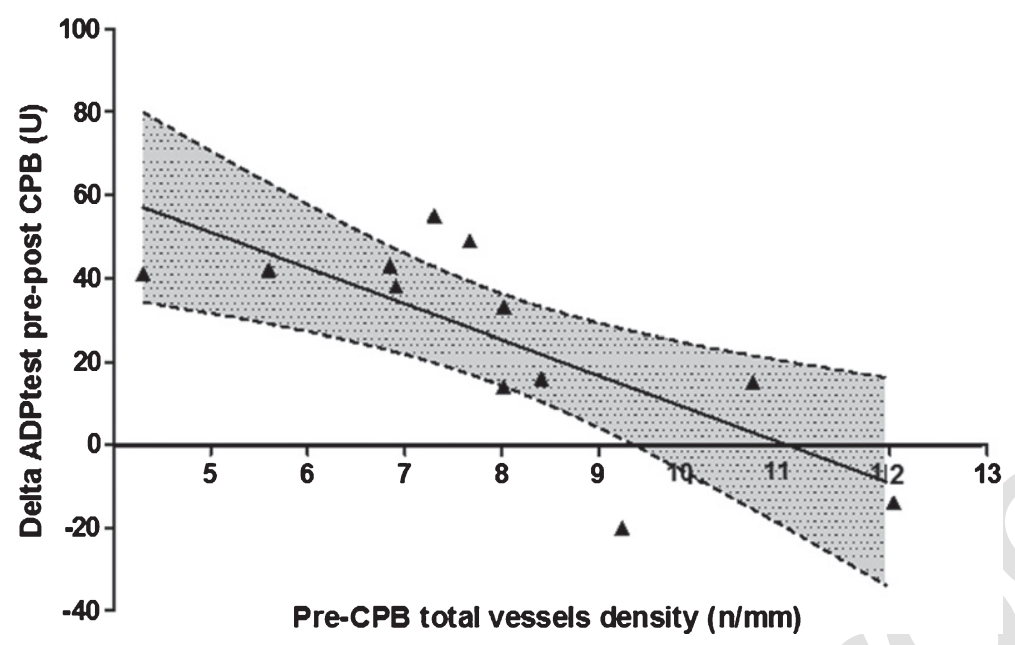

Fig. 5. Linear regression analysis for association between pre-cardiopulmonary bypass (CPB) total vessels density and preto post-CPB multiple electrode aggregometry (MEA) changes in ADPtest. Dashed lines delimit the $95 \%$ confidence interval (gray zone).

pre-CPB PVD and TVD: for both these measures of the microcirculatory status, higher values correspond to a better platelet function preservation, especially in terms of platelet reactivity to ADP-mediated stimulation of the $\mathrm{P}_{2} \mathrm{Y}_{12}$ receptor.

This relationship can be interpreted in terms of a protective effect of a well-working microcirculation against the effects of CPB: in fact, pre-CPB TVD has a negative association with the pre-post $\mathrm{CPB}$ difference in platelet count $(P=0.043)$ and an even stronger association with the pre-post $\mathrm{CPB}$ difference in platelet function at the ADPtest $(P=0.006)$ and the TRAPtest $(P=0.039)$.

Cardiac surgery with CPB exerts deleterious effects on the microcirculatory conditions, with a generalized loss of functional capillary density, and increased flow heterogeneity [7-9]. Additionally, both platelet count and function show a generalized decrease [11] which is one of the determinants of postoperative bleeding [21].

Our study confirms these findings, both in terms of microcirculation impairment and platelet loss of function. Our results link these changes together, opening the window for a number of possible interpretations.

In previous studies using the SDF technology, cardiac surgery with CPB decreased the functional capillary density [8], as well as the proportion and density of perfused small vessels [7], and these changes are irrespective of hemodynamic changes [22]. The main mechanisms underlying this microvascular perfusion impairment are inflammatory and endothelial activation [9]. Endothelial dysfunction in particular is advocated to play a major role through a glycocalyx alteration [9]. Glycocalyx disruption is associated with cardiovascular disease, and measures of glycocalyx integrity are possible with the SDF technology [23]. Damage of the glycocalyx disrupts the natural anti-inflammatory and anti-coagulant properties of the endothelium, and may create a prothrombotic condition triggered by platelet adhesion to the endothelial surface and subsequent platelet aggregation. In other clinical conditions where the glycocalyx is disturbed (like sepsis), platelet rolling and adsorption to the endothelial surface is considered both a determinant and a consequence of the observed microvascular perfusion alterations [24].

During CPB, platelets are activated by contact with the foreign surfaces, shear stress, inflammation and coagulation factors. In particular, thrombin is extensively formed on CPB, due to the release of tissue factor from the surgical wounds [25]. Thrombin is a powerful platelet activator through the 
protease-activated receptors (PAR); the extensive and continuous platelet activation on CPB determines platelet exhaustion and loss of function. This mechanism is clearly confirmed by our data, with a significant decrease of platelet function at the ADPtest and the TRAPtest (exploring PAR-reactivity) after CPB. Additionally other mechanisms may contribute to this pattern. An important determinant of both platelet adhesion and aggregation processes is the shear stress. At an elevated shear stress both the von Willebrand Factor (vWF) and the GPIb-IX-V complex change their conformation and increase their affinity [26]. Additionally, an elevated shear stress triggers platelet aggregation through binding of the vWF to the GPIb-IX-V complex in the fluid phase [27]. The conformational change of the vWF leads to a higher accessibility of the VWF-A1 domain which is the most important epitope for bridging between platelets or surfaces and which is hidden as long the vWF is circulating in a globular shape $[28,29]$.

In summary, our interpretation of the link between a pre-CPB altered microcirculation and the loss of platelet count and function during CPB is that an altered endothelium, together with an increased shear stress and the release of pro-inflammatory and pro-coagulant factors is the determinant of platelet activation, adhesion, aggregation, and consequent loss of number and function. Conversely, a wellworking microcirculation is associated with a lower degree of CPB-induced platelet dysfunction, probably through the maintenance of its anti-inflammatory and anti-coagulant properties.

There are limitations in our study. The main one is the limited patient population. With larger sample sizes, it could be possible to link the microcirculation and platelet-related changes to clinically relevant outcomes, like postoperative bleeding and thrombotic events. A second limitation is that we could not deeply explore the endothelial function with specific techniques like flow-mediated dilation and/or measure of specific endothelium-derived mediators. Despite this, we believe that our data may be relevant for understanding the complex pathophysiology of CPB-related changes in both microcirculation and platelet function.

\section{Acknowledgments}

This study was supported by Italian Ministry of Health, grant GR-2013-02356272 to V. Bari and by an external support by Roche Diagnostics, which provided the Multiplate reagents free of charge.

\section{References}

[1] Badimon L, Bugiardini R, Cenko E, Cubedo J, Dorobantu M, Duncker DJ, et al. Position paper of the European Society of Cardiology-working group of coronary pathophysiology and microcirculation: Obesity and heart disease. Eur Heart J. 2017;38:1951-8.

[2] Martens RJ, Vink H, van Oostenbrugge RJ, Staals J. Sublingual microvascular glycocalyx dimensions in lacunar stroke patients. Cerebrovasc Dis. 2013;35:451-4.

[3] Mulders TA, Nieuwdorp M, Stroes ES, Vink H, Pinto-Sietsma SJ. Non-invasive assessment of microvascular dysfunction in families with premature coronary artery disease. Int J Cardiol. 2013;168:5026-8.

[4] Jaarsma C, Vink H, van Haare J, Bekkers SCAM, van Rooijen BD, Backes WH, et al. Non-invasive assessment of microvascular dysfunction in patients with microvascular angina. Int J Cardiol. 2017;248:433-9.

[5] Braune S, Groß M, Walter M, Zhou S, Dietze S, Rutschow S, et al. Adhesion and activation of platelets from subjects with coronary artery disease and apparently healthy individuals on biomaterials. J Biomed Mater Res B Appl Biomater. 2016;104:210-7.

[6] Reinthaler M, Braune S, Lendlein A, Landmesser U, Jung F. Platelets and coronary artery disease: Interactions with the blood vessel wall and cardiovascular devices. Biointerphases. 2016;11:029702.

[7] De Backer D, Dubois M-J, Schmartz D, Koch M, Ducart A, Barvais L, et al. Microcirculatory alterations in cardiac surgery: Effects of cardiopulmonary bypass and anesthesia. Ann Thorac Surg. 2009;88:1396-403. 
[8] Atasever B, Boer C, Goedhart P, Biervliet J, Seyffert J, Speekenbrink R, et al. Distinct alterations in sublingual microcirculatory blood flow and hemoglobin oxygenation in on-pump and off-pump coronary artery bypass graft surgery. J Cardiothorac Vasc Anesth. 2011;25:784-90.

[9] Konig Nj, Atasever B, Vonk A, Boer C. Changes in microcirculatory perfusion and oxygenation during cardiac surgery with or without cardiopulmonary bypass. J Cardiothorac Vasc Anesth. 2014;28:1331-40.

[10] Ranucci M, Baryshnikova E, Soro G, Ballotta A, De Benedetti D, Conti D. Multiple electrode whole-blood aggregometry and bleeding in cardiac surgery patients receiving thienopyridines. Ann Thorac Surg. 2011;91:123-9.

[11] Agarwal S, Johnson RI, Kirmani BH. Pre- and post-bypass platelet function testing with multiple electrode aggregometry and TEG platelet mapping in cardiac surgery. J Cardiothorac Vasc Anesth. 2015;29:1272-6.

[12] Jung F, Braune S. Thrombogenicity and hemocompatibility of biomaterials. Biointerphases. 2015;11:029601.

[13] Olechowski B, Khanna V, Mariathas M, Ashby A, Dalton RT, Nordon I, et al. Changes in platelet function with inflammation in patients undergoing vascular surgery. Platelets. 2017;11:1-9.

[14] Orvin K, Barac YD, Kornowski R, Perl L, Wasserstrum Y, Rubchevsky V, et al. Monitoring platelet reactivity during prasugrel or ticagrelor washout before urgent coronary artery bypass grafting. Coron Artery Dis. 2017;28:465-71

[15] Gruzdeva O, Uchasova E, Fanaskova E, Akbasheva O, Penskaya T, Plotnikov G, et al. Use of thrombin generation test for monitoring hemostasis in coronary bypass surgery. Clin Hemorheol Microcirc. 2017;66:57-66.

[16] Mazzeffi M, Lund L, Wallace K, Herrera AV, Tanaka K, Odonkor P, et al. Effect of cardiopulmonary bypass on platelet mitochondrial respiration and correlation with aggregation and bleeding: A pilot study. Perfusion. 2016;31:508-15.

[17] De Backer D, Hollenberg S, Boerma C, Goedhart P, Büchele G, Ospina-Tascon G, et al. How to evaluate the microcirculation: Report of a round table conference. Crit Care. 2007;11:R101.

[18] Ince C. Sidestream dark field (SDF) imaging: An improved technique to observe sublingual microcirculation. Crit Care. 2005;8(suppl 1):72.

[19] Goedhart PT, Khalilzada M, Bezemer R, Merza J, Ince C. Sidestream dark field (SDF) imaging: A novel stroboscopic LED ring-based imaging modality for clinical assessment of the microcirculation. Opt Express. 2007;15:15101-14.

[20] Trzeciak S, Dellinger RP, Parrillo JE, Guglielmi M, Bajaj J, Abate NL. Early microcirculatory perfusion derangements in patients with severe sepsis and septic shock: Relationship to hemodynamics, oxygen transport, and survival. Ann Emerg Med. 2007;49:88-98.

[21] Ranucci M. Hemostatic and thrombotic issues in cardiac surgery. Semin Thromb Hemost. 2015;41:84-90.

[22] Den Uil CA, Lagrand WK, Spronk PE, van Domburg RT, Hofland J, Lüthen C, et al. Impaired sublingual microvascular perfusion during surgery with cardiopulmonary bypass: A pilot study. J Thorac Cardiovasc Surg. 2008;136:129-34.

[23] Vlahu CA, Lemkes BA, Struijk DG, Koopman MG, Krediet RT, Vink H. Damage of the endothelial glycocalyx in dialysis patients. J Am Soc Nephrol. 2012;23:1900-8.

[24] De Backer D, Orbegozo Cortes D, Donadello K, Vincent J-L. Pathophysiology of microcirculatory dysfunction and the pathogenesis of septic shock. Virulence. 2014;5:73-9.

[25] Edmunds LH, Colman RW. Thrombin during cardiopulmonary bypass. Ann Thorac Surg. 2006;82:2315-22.

[26] Peterson DM, Stathopoulos NA, Giorgio TD, Hellums JD, Moake JL. Shear-induced platelet aggregation requires von Willebrand factor and platelet membrane glycoproteins Ib and IIb-IIIa. Blood. 1987;69:625-8.

[27] Kroll MH, Hellums JD, McIntire LV, Schafer AI, Moake JL. Platelets and shear stress. Blood. 1996;88:1525-41.

[28] Chen W, Luo J, Zhu C. Molecular dynamics simulated unfolding of von Willebrand Factor A domains by force. Cell Mol Bioeng. 2009;2:75-86.

[29] Schneider SW, Nuschele S, Wixforth A, Gorzelanny C, Alexander-Katz A, Netz RR, et al. Shear-induced unfolding triggers adhesion of von Willebrand factor fibers. Proc Natl Acad Sci U S A. 2007;104:7899-903. 